\title{
A New Method for Detecting Stable and Unstable Power Swings
}

\author{
Shubham S. Medhekar \\ Electrical Engineering Department \\ Walchand Collage of Engineering \\ Sangli, India
}

\author{
Ramchandra P. Hasabe \\ Electrical Engineering Department \\ Walchand Collage of Engineering \\ Sangli, India
}

\begin{abstract}
The incorrect functioning of the zone 3 of distance relay has been perceived as one of those main reasons for power system outages. The zone 3 of distance relay may operate incorrectly in power swing conditions. If the occurred power swing is a stable one then we need to block the distance relay's zone 3 and if the occurred power swing is unstable one then the zone 3 tripping must occur. So for this purpose proper identification of power swing is essential. This research gives a reliable and fast method for power swing identification. The method suggested is referred as FZC method. The proposed method determines the synchronous machine's relative speed from local relay measurement. If the synchronous machine's relative speed is going through a point of zero crossing, then the power swing is categorized as a stable one and if the relative speed do not cross the zero point then the power swing is characterized as an unstable one. This approach do not require any detailed offline studies to determine the relay setting as it is a method based on local measurement. It analyzes the system from stability point of view. An SMIB test system is used for checking the reliability and performance of the technique proposed in this paper.
\end{abstract}

Index Terms-Transmission line, Distance protection, power swing.

\section{INTRODUCTION}

Distance relay operation is established on measurement of the impedance at the point of operation of the relay, which indeed is directly proportional to distance of occurrence of fault and does not depend on fault current level [2]. As an instance of being very simple (as this method is established on local measurement), it is commonly used for transmission line protection. The modern Trend for implementation of the distance protection scheme is "think globally but act locally".

Standard distance protection scheme is implemented and

executed by separating executed the power system in different protective zones such as zone 1 , zone 2 etc. In which fault is detected and is eliminated by disconnecting least or minimum portion of transmission line network. When fault occurs in the transmission lines, the prime relay is automatically assigned to operate. In general three zones are implemented for the backup protection of the remote section of the transmission line network. The zone 3 of the distance relay is a zone of overreaching hat provides remote backup protection if the primary local protective zone or the zone 2 protection is failing for a contingency condition occurred locally.

Intentional delay in time for the zone 3 backup protection is generally 1-2 seconds for correct coordination. The distance relay's improper operation may occur during various transient stability conditions such as power swings etc. and various conditions of voltage instability. The distance relay's extended reach is beneficial if we look from the perspective of system security but it may contradict with load ability requirement of the line. The undesired operation of zone 3 of the distance relay is considered as one among the major reasons for outages in power system [3] - [5]. The conditions such as stable power swings are not deleterious to the power system network. But sometimes it may interlope into the distance relay's zone 3 and cause incorrect operation. So the correct operation of the $3 \mathrm{rd}$ zone of the distance relay is important so as to avoid failure of large part of power system network.

Proper identification of a stable swing and finally blocking it is very censorious for proper operation of the distance relay. The conventional blender scheme used for the detection of the power swing determines difference in the rate in change of the positive sequence impedance vector [6]. It is not convenient to find each and every scenario of power swing and different operating conditions on a large network. Also to find a precise location for blocking of the swing and to separate the faulty portion requires a lots of stability studies. There are various other schemes that are similar to the conventional blinder scheme: A method based on rate of change of resistance [7]. The one way to improve the functioning of the distance relay for power swing conditions and heavy loads is to change the distance relays characteristics. The mho characteristics angle adjustment is given in [3]. The other similar method includes changing the zone shape of the distance relay, a supervisor zone tripping scheme, studying the load encroachment characteristics etc. [3]. All these method are characterized as zone changing characteristics. The problem associated with all these methods is similar to that with the conventional blinder scheme. We need to find loci of the power swing after doing various stability studies and all scenarios of power swing are not covered and different operating conditions are included.

In [8] a swing-center voltage (SVC) technique is given, which discovers the rate in the change in swing-center voltage of the power system network to find out whether it is an unstable condition or a stable power swing. The method of determining the swing-center voltage is not dependent on the source impedance of the network and impedance of the line. Its magnitude is equivalent to the variation in source angle and it is in strictly between 0 to 1 per unit [8]. This scheme is only relevant for a system having only two-sources. There is not a single literature available considering the SVC method applied for large power system network. A pattern identification method is also tested for identification of power swing. In [9] a Wavelet Transform method is given of 
identification of swing. In [10] a Support Vector Machine (SVM) method used for detection power the power swing is given. A polynomial curve fitting technique used for blocking zone 3 was given in [11]. In [12] a method which is using transient monitoring function for protection of zone 3 is given. The pattern identification method requires training using many simulation runs in offline fashion. Polynomial curve fitting method might be inconvenient in applying to the power system network if the power system network is on the verge of in stability conditions.

The purpose of the paper is giving a dependable power swing identification method which can identify weather the power swing is stable or unstable intruding into zone 3 by employing the FZC method. This method can be further used for blocking zone 3 of the distance relay for stable power swing condition and to prevent the unwanted tripping of distance relay. Extensive studies of power system stability are not required for determining the distance relay setting unlike the traditional blinder scheme is the primary advantage of this method. The input quantities required for this method are simple electrical quantities that can be measured locally on the transmission line network.

The paper is organized as follows: Section II explains the concept of stable and unstable power swing and the first zero crossing with proper example. Section III gives the proposed method Section IV consist of the test system i.e. the SMIB model. Section V consists of the result analysis and Section $\mathrm{VI}$ gives the final conclusion.

\section{POWER SWING AND FIRST ZERO CROSSING}

There exists a power balance between the consumed and generated active and reactive powers in the power system network under balanced steady state condition. But when a large disturbance occurs, e.g. faults, line switching, disconnection of generators, and the loss of large block of loads, it results in sudden change of electrical power consumption. As the mechanical input to the generator is constant, the disturbance triggers the machine rotor angle to oscillate and thus results in electrical power swing. This results in electro mechanical oscillations in the system causing fluctuation in voltage and current. Consequently the power flow between the inter connected parts also starts oscillating. Power swings are the variation caused in power flow when the internal voltage of the generator at different level start slipping with respect to each other. If a new stable equilibrium is reached after the disturbance, then the swing is referred as a stable power swing. If a new equilibrium is not reached after the disturbance, the swing is referred as unstable power swing.

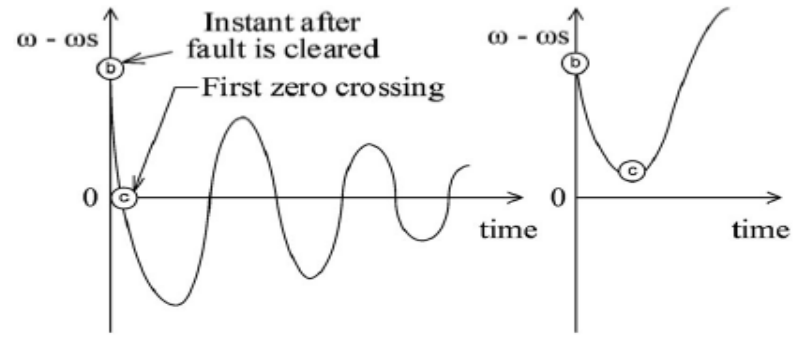

Fig. 1.Relative Speed of machine during stable and unstable power swing.

A stable power swing can be differentiated from an unstable one based on the known fact that the synchronous machine's relative speed reaches zero before accelerating again. In Fig. 1.we can see that if $b$ is the instant at which the disturbance is removed, then if the swing generated is a stable power swing if the relative speed crosses a zero point i.e. c before accelerating again. If the swing generated is an unstable one then the machine relative speed starts accelerating again without crossing zero point.

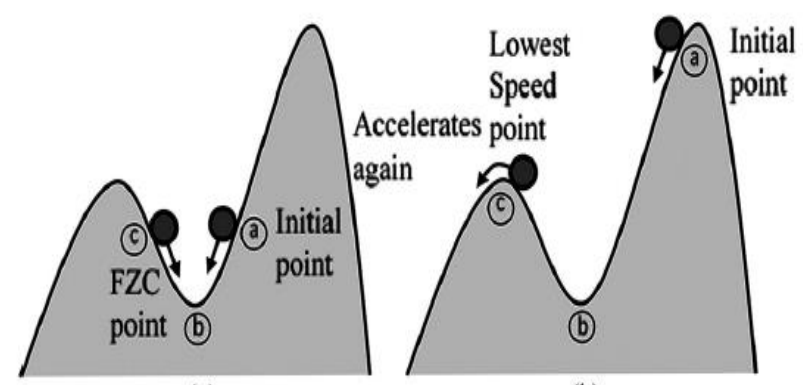

(a)

(b)

Fig. 2. Equilibrium points for stable and unstable power swings in Fig. 1.

Fig. 2 explains the concept of stable and unstable power swing which is given in Fig. 1 from the view point of physics (with the help of balance points). The point ' $a$ ' correlates with the instance when the fault is happening i.e. when the relative speed is a zero value, point ' $b$ ' correlates with the instance when the fault is removed i.e. if the speed is reaching the highest value and point ' $c$ ' correlates with the point of zero crossing (which is only for stable power swing) or the point of least speed (which is only for unstable power swing).

\section{PORPOSED FIRST ZERO CROSSING SCHEME}

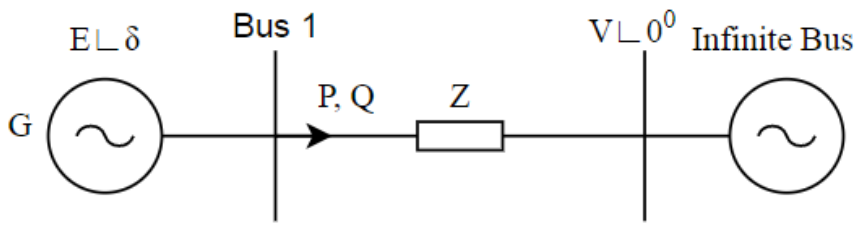

Fig. 3.Single machine infinite bus system.

The Fig. 3 shows a SMIB system. The real power $P$, reactive power $Q$ and voltage $E \angle \delta$ are measured locally at the relay. Voltage $V \angle O$ is the infinity bus voltage or slack bus voltage. In phase one of the proposed method we calculate the two unknown quantities i.e. the equivalent system reactance/impedance $Z$ and load angle $\delta$

The power flow equations for the SMIB system are given as follows:

$$
\begin{gathered}
P=\frac{E V}{Z} \operatorname{Sin} \delta \\
Q=\frac{E^{2}}{Z}-\frac{E V}{Z} \operatorname{Cos} \delta
\end{gathered}
$$

Writing (1) and (2) in terms of $\operatorname{Sin} \delta$ and $\operatorname{Cos} \delta$ we get 


$$
\begin{gathered}
\operatorname{Sin} \delta=\frac{P Z}{E V} \\
\operatorname{Cos} \delta=\frac{E^{2}-Z Q}{E V}
\end{gathered}
$$

Now eliminating $\delta$ in equations (3) and (4) we get

$$
\begin{gathered}
\left(\frac{P X}{E V}\right)^{2}-\left(\frac{E^{2}-Z Q}{E V}\right)=1 \\
\left(P^{2}+Q^{2}\right) Z^{2}+2 E^{2} Z Q+E^{4}-E^{2} V^{2}=0
\end{gathered}
$$

By solving (6) which is obtained from (5) we get the equivalent system reactance/impedance. This completes the phase one of the method.

With calculation of the equivalent impedance $Z$ the phase two of the method is determining the synchronous machine relative speed.

Differentiating (3) we get:

$$
\frac{d P}{d t}=\left(\frac{E V}{Z}\right) \operatorname{Cos} \delta\left(\frac{d \delta}{d t}\right)
$$

Where,

$$
\begin{gathered}
\omega_{r}=\frac{d \delta}{d t} \text { and } \operatorname{Cos} \delta=\frac{E^{2}-Z Q}{E V} \\
\omega_{r}=\frac{\left(\frac{d P}{d t}\right)}{\left(\frac{E^{2}-Z Q}{E V}\right)}
\end{gathered}
$$

Here $\omega_{r}$ the synchronous machine's relative speed and it is acquired until $d P / d t$ is acquired from given digital simulation.

$$
\frac{d P}{d t} \approx \frac{\Delta P}{\Delta t}=\frac{P_{t}-P_{(t-1)}}{\Delta t}
$$

So the synchronous machine's relative speed can be given by

$$
\omega_{r}=\left(\frac{\left(\frac{P_{t}-P_{(t-1)}}{\Delta t}\right)}{\left(\frac{E^{2}-Z Q}{E V}\right)}\right)
$$

If the actual rotor speed is given by the variable $\omega_{r}$ then the synchronous machine's relative speed can be given by

$$
\omega_{r}=\omega-\omega_{s}
$$

Where $\omega_{s}$ is the synchronous speed and is given by $2 \pi f_{s}$ where $f_{s}$ is the synchronous frequency.

If the synchronous machine's relative speed i.e. $\omega_{r}$ crosses a zero point (as discussed in section II) then the power swing can be considered as a stable swing and if it is not crossing a zero point then it is considered as a unstable power swing.

\section{TEST SYSTEM}

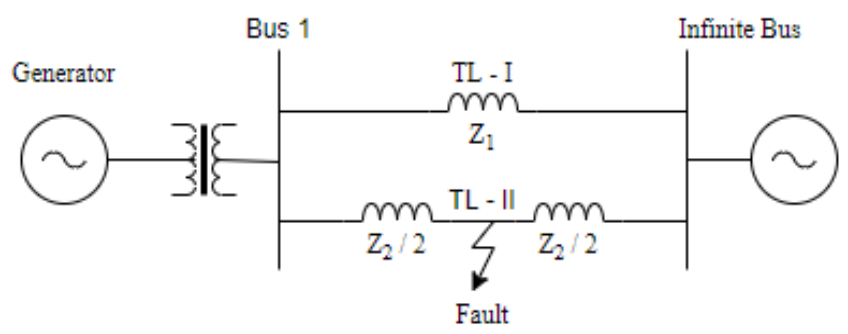

Fig. 4. Test system

The proposed method is tested on the given test system. The test system is built in MATLAB software. It consists of a generator, a transformer, two parallel transmission line i.e. TL-I and TL-II of equal length and same parameters and infinite bus. For generating power swing a three phase to ground fault is created in the center of TL-II. A three phase to ground fault of time duration 0.4 second is created in the center of TL-II for generating a stable power swing and a fault of duration 0.5 second is created for generating unstable power swing. A numerical optimization technique known as the Laguerre method has been used for solving the polynomial equation of $Z$ for determining its value. Then this value of $Z$ and the variation in active power i.e. $d P / d t$ is used to determine the synchronous machine's relative speed i.e. $\omega_{r}$ and from that the identification of stable and unstable power swing can be done.

\section{SIMULATION RESULT AND DISCUSSION}

The test system given in Fig. 4.has been created in MATLAB software. The proposed first zero crossing scheme given in Section III is implemented on the test system given in Fig. 4. In MATLAB software itself and the results are validated.

\section{A. Stable power swing}

For generating a stable power swing a three phase to ground fault of duration 0.4 second is created on TL-II as shown in fig. The switching instance of fault is $0.1-0.5$ second. The magnitude of voltage $\mathrm{E}$ and the relative speed are shown below. From fig we can see that the voltage $E$ is reaching a steady state value after a disturbance is applied at 0.1 seconds and removed at 0.5 seconds i.e. for duration of 0.4 seconds. This is happening because the swing generated is a stable power swing. Fig is of the synchronous machine's relative speed and is obtained after implementing the proposed method on the test system. We can see that the relative speed is crossing a zero value before accelerating again i.e. First Zero Crossing is happening. This is due to the fact that a stable power swing is created on the test system. 


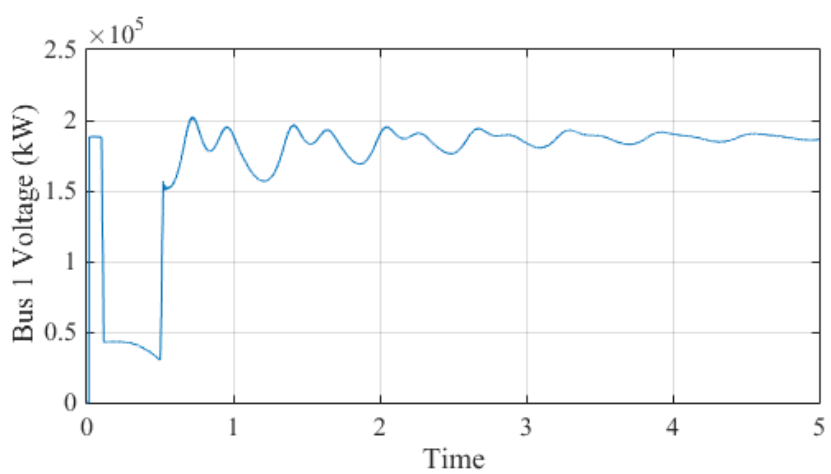

Fig. 5. Voltage at bus 1 during stable power swing.

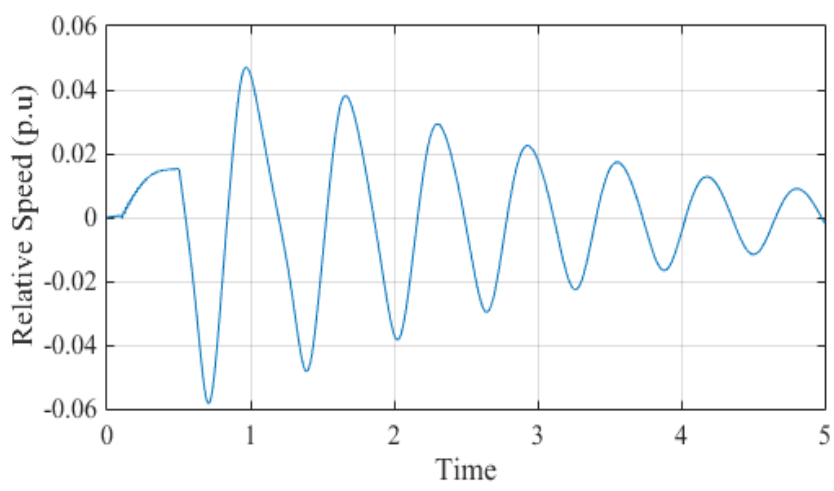

Fig. 6.Machine's relative speed during stable power swing.

\section{B. Unstable power swing}

For generating an unstable power swing a three phase to ground fault of duration 0.5 second is created on TLII as shown in fig. The switching instance of fault is 0.1-0.6 second. The magnitude of voltage $\mathrm{E}$ and the relative speed are shown below. From fig we can see that the voltage $\mathrm{E}$ is not reaching a steady state value rather it is oscillating after a disturbance is applied at 0.1 seconds and removed at $0.6 \mathrm{sec}$ i.e. for duration of 0.5 seconds. This is happening because the swing generated is an unstable power swing. Fig is of the synchronous machine's relative and is obtained after implementing the proposed method on the test system. We can see that the relative speed is not crossing a zero value before accelerating again i.e. First Zero Crossing is not happening. This is due to the fact that an unstable power swing is created on the test system.

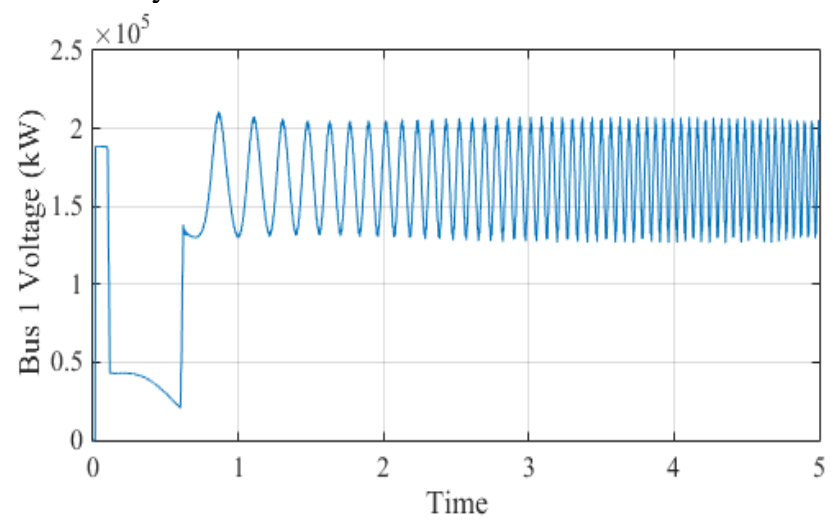

Fig. 7.Voltage at bus 1 during unstable power swing.

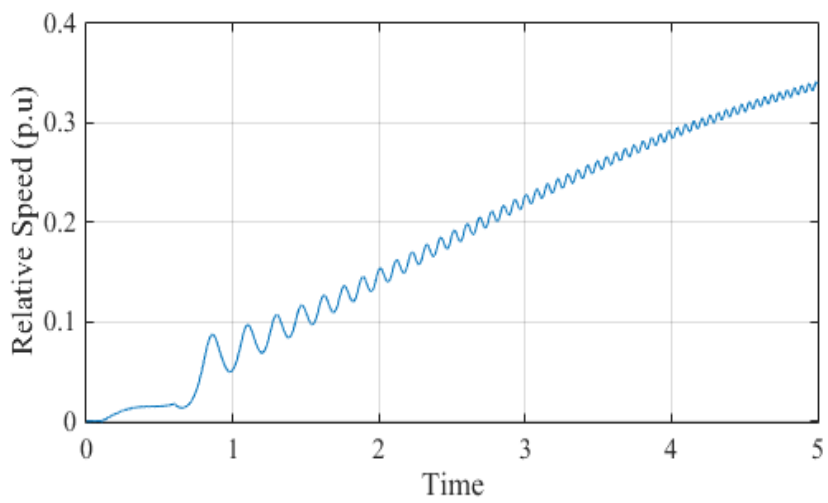

Fig. 8.Machine's relative speed during unstable power swing

\section{CONCLUSION}

This paper gives a technique to detect stable and unstable power swing. The synchronous machine's relative speed is analyzed with respect to time to differentiate between stable and unstable power swing (by observing at the first zero crossing in time axis). The testing of this method has been done on a single machine infinite bus test system. The proposed method does not require detail analysis of the system. As the proposed method is a local measurement based method it is very convenient and simple.

\section{REFERENCES}

[1] D. Kang and R. Gokaraju, "A new method for blocking third zone distance relays during stable power swings", IEEE Trans. Power Del., vol. 31, no. 4, pp. 1836-1843, Aug. 2016.

[2] S. H. Horowitz and A. G. Phadke, "Nonpilot distance protection of transmission lines," Power System Relaying 3rd, Hoboken, NJ, USA: Wiley, 2008.

[3] W. A. Elmore, "Line and circuit protection," Protective Relaying Theory and Applications, New York, USA: Marcel Dekker, 2004

[4] IEEE PSRC Working Group D4, "Application of overreaching distance relays," 2009

[5] S. H. Horowitz and A. G. Phadke, "Third zone revisited," IEEE Trans. Power Del., vol. 21, no. 1, pp. 23-29, Jan. 2006.

[6] M. McDonald et al. IEEE PSRC Working Group D6, "Power swing and out-of-step considerations on transmission lines," Jun. 2005.

[7] Z. D. Gao and G. B. Wang, "A new power swing block in distance protection based on a microcomputer principle and performance analysis," in Proc. Int. Conf. Adv. Power Syst. Control Oper. Manage., 1991, pp. 623-628.

[8] G. Benmouyal, D. Tziouvaras, and D. Hou, "Zero-setting powerswing blocking proctection," 31st Annu. Western Protect. Relay Conf., Spokane, WA, USA, Oct. 19-21 2004

[9] S. M. Brahma, "Distance relay with out-of-step blocking function using wavelet transform," IEEE Trans. Power Del., vol. 22, no. 3, pp. 1360-1366, Jul. 2007.

[10] K. Seethalekshmi, S. N. Singh, and S. C. Srivastava, "SVM based power swing identification scheme for distance relays," in Proc IEEE Power Energy Soc. Gen. Meeting, 2010, pp. 1-8.

[11] C. Sriram, D. R. Kumar, and G. S. Raju, "Blocking the distance relay operation in third zone during power swing using polynomial curve fitting method," in Proc. Int. Conf. Smart Elect. Grid, 2014, pp. 1-7.

[12] P. K. Nayak, A. K. Pradham, and P. Bajpai, "Secured zone 3 protection during stressed condition," IEEE Trans. Power Del., vol. 30, no. 1, pp. 89-96, Feb. 2015.

[13] P. M. Anderson and A. A. Fouad, "Classical stability study of a 9-bus system," Power System Control and Stability 2nd, Hoboken, NJ, USA: Wiley, 2004. 
[14] Y. Xue, T. Van Custem, and M. Ribbens-Ravella, "Extended equal area criterion justifications, generalizations, applications," IEEE Trans. Power Syst., vol. 4, no. 1, pp. 44-52, Feb. 1989

[15] B. Shrestha, R. Gokaraju, and M. Sachdev, "Out-of-step protection using state-plane trajectories analysis," IEEE Trans. Power Del., vol. 28, no. 2, pp. 1083-1093, Apr. 2013 